\section{RECRUITMENT OF YOUNG PRACTITIONERS}

The Central Medical War Committee is issuing the following circular to hospital authorities in England and Wales. A similar circular will be issued in Scotland by the Scottish C.M.W.C.

\section{DeAR Sir,}

\section{Recruitment from “A A Posts}

1. The Central Medical War Committee has recently experienced great difficulty in obtaining the numbers of medical recruits required by H.M. Forces and it has become clear that exceptional measures are necessary if the recruitment of medical practitioners during the remainder of this year is not to fall far short of the requirements of the Services.

2. On the recommendation of the Medical Priority Committee the Minister of Health, with the concurrence of the Secretary of State for Scotland, has now instructed the Central Medical War Committee that young practitioners who are liable for military service and who complete a six months' tenure of " A" posts in hospitals during the second half of 1948 must be recruited on the termination of their "A " appointments and must not be permitted to proceed to "B2" posts. Appeals for deferment will not be considered by the Central Medical War Committee in such cases, but a practitioner will retain the right to appeal against recruitment on the ground of conscience and to appeal for postponement of recruitment on the ground of exceptional personal hardship.

3. A practitioner whose "A" appointment terminates before he has occupied it for six months will be permitted (subject to what is said in para. 5 below) to occupy another "A " appointment for the remainder of the six months' period, but will not be allowed to proceed to a "B2" post. In the exceptional case in which the first post held after medical qualification is not in the "A" category, the practitioner will be recruited after a six months' tenure of the post.

4. This is to be regarded as a temporary emergency measure, and the need for its continuance will be reviewed towards the end of the year. The Central Medical War Committee will be glad if hospital authorities will kindly arrange for it to be brought to the notice of those practitioners in their employment who will be affected by it.

\section{Recruitment before the 26th Birthday}

5. I am asked to inform you also that in future all practitioners, liable for military service, who are below the age of 26 on their admission to the Medical Register will be recruited before they reach their 26th birthday, even if this should prevent them from completing the normal period of six months in an "A" post, or from occupying an "A" post at all. It follows that a hospital which appoints to an " A " post a practitioner who will attain the age of 26 during the six months following the commencement of the appointment will not be able to retain his services for the normal period. The urgent need to increase the number of recruits makes it necessary to adopt this procedure, as a practitioner granted deferment in an "A" post beyond his 26th birthday is no longer liable to compulsory recruitment. The same procedure will be adopted in the exceptional case of the newly qualified practitioner approaching the age of 26 who is appointed to a " B2" or other post without having first held an " $A$ " appointment. In such a case the practitioner will not be permitted to hold the post for six months if this would prevent his recruitment being effected before his 26th birthday.

\section{Summary}

6. (i) A young practitioner, liable for military service, who completes a six months' tenure of one or more "A " posts on or after July 1, 1948, will be recruited forthwith and will be allowed to appeal only on the ground of conscience or on the ground of except:onal personal hardship. Similarly, a practitioner whose first post after medical qualification is not in the "A" category will be recruited after he has held the post for six months. This modification of the present regulations governing deferment of recruitment will be reviewed towards the end of 1948. (ii) A young practitioner below the age of 26 , and liable for military service, will not in future be allowed to hold an "A" or other post, or to complete the normal tenure of the post, if this would prevent his recruitment being effected before his 26 th birthday.

(iii) Hospital authorities are invited to assist the Central Medical War Committee by bringing these decisions to the notice of practitioners in their employment who will be affected by them.

$$
\begin{aligned}
& \text { Yours faithfully, } \\
& \text { CharLes HiLl, } \\
& \text { Secretary. }
\end{aligned}
$$

\section{NATIONAL HEALTH SERVICE \\ Supplementary Ophthalmic Services : Notice to Ophthalmologists}

It is understood that the Ophthalmic Services Committee of each Executive Council will be required to publish a list of medical practitioners and opticians, having the prescribed qualifications, who undertake to test sight on the terms obtaining in the Committee's area. The expression "medical practitioner having the prescribed qualifications" means a medical practitioner who has :

" (a) completed an academic or postgraduate course in ophthalmology approved by the Committee hereinafter in this paragraph mentioned, and received a diploma or certificate in respect of this course; or

(b) held for a period of two years an appointment as an ophthalmic surgeon or assistant ophthalmic surgeon on the staff of an eye hospital or a hospital having a special eye department; or

(c) held any appointment for a period of two years affording special opportunities for acquiring the necessary skill and experience of the kind required for the services to be rendered; or

(d) had immediately before the appointed day his name included in the list of medical practitioners prepared by either the B.M.A., the National Ophthalmic Treatment Board, or the Incorporated Ophthalmic Council, for use by Approved Societies for the purpose of ophthalmic benefit under the National Health Insurance Act, 1936;

and who shall, to the satisfaction of the Minister, acting on the advice of a Committee to be recognized by him for the purpose of approving such qualifications, have had adequate, including recent, experience."

The central professional Committee referred to above has been recognized by the Minister and is composed of practitioners nominated by the B.M.A. and the Faculty of Ophthalmologists. This Committee has the duty of compiling a central list of medical practitioners having the prescribed qualifications. The Committee therefore invites applications from all ophthalmic medical practitioners to be included in the central list, which is an essential preliminary to inclusion in local lists for which separate application must be made to the Ophthalmic Services Committees of the Executive Councils concerned.

Inclusion in the central list is entirely without prejudice to future action and it will be open to every practitioner to decide, when he knows the terms of service. whether he will take part in the Supplementary Ophthalmic Service or not. Ophthalmic practitioners should not, however, await the publication of the terms of service before applying for recognition by the central committee.

All ophthalmic practitioners are therefore requested to apply as soon as possible to the Secretary, Ophthalmic Qualifications Committee, B.M.A. House, Tavistock Square, W.C.1, giving the necessary evidence that they comply with the criteria outlined above. It is particularly important that details of recent experience should be included.

\section{CORRECTIONS TO PROGRAMME OF ANNUAL MEETING}

In the section of Anatomy and Anthropology Dr. D. V. Davies is the only Honorary Secretary.

In the section of Neurology and Psychiatry Dr. Denis Williams, F.R.C.P., and Mrs. A. V. Hill have been invited to speak at the discussion on "The Early Recognition and Management of Senile Deterioration." 